\title{
Environmental determinants of motile cryptofauna on an eastern Pacific coral reef
}

\author{
Ian C. Enochs ${ }^{1,2, *}$, Lauren T. Toth ${ }^{3}$, Viktor W. Brandtneris ${ }^{4}$, Jamie C. Afflerbach ${ }^{4}$, \\ Derek P. Manzello',2
}
${ }^{1}$ Cooperative Institute for Marine and Atmospheric Sciences, Rosenstiel School of Marine and Atmospheric Science, University of Miami, 4600 Rickenbacker Cswy., Miami, Florida 33149, USA
${ }^{2}$ Atlantic Oceanographic and Meteorological Laboratories (AOML), National Oceanographic and Atmospheric Administration (NOAA), 4301 Rickenbacker Cswy., Miami, Florida 33149, USA
${ }^{3}$ Department of Biological Sciences, Florida Institute of Technology, 150 West University Boulevard, Melbourne, Florida 32901, USA

${ }^{4}$ Rosenstiel School of Marine and Atmospheric Science, University of Miami, 4600 Rickenbacker Cswy., Miami, Florida 33149, USA

\begin{abstract}
Coral reef cryptofauna, which live hidden within reef framework structures, are considered to be the most diverse group of coral reef metazoans. They likely comprise more biomass than all surface fauna, providing food sources for fishes and playing important roles as predators, herbivores, detritivores, filter feeders, and scavengers. In an era of global change, it is necessary to determine how these communities are structured across reef habitats as well as to understand how reef framework degradation will impact the cryptofauna and, by extension, ecosystem function. Artificial reef framework units were constructed from coral rubble to approximate framework substrates. Forty replicates were subjected to treatments of differing porosity, flow, and coral cover in a fully crossed ANOVA design. After $2 \mathrm{mo}$ in situ, all motile cryptofauna (>2 $\mathrm{mm}$ ) were counted, weighed, and identified to the lowest possible level. A total of 11309 specimens were collected, comprising $>121$ species from 6 separate phyla. Cryptofaunal abundances and biomass were higher in low-porosity crypts and biomass was greater in slow-flow environments, highlighting the importance of sheltered low-porosity habitats, such as back-reef rubble plains. The presence of live coral was not found to have a significant effect on the motile cryptofauna occupying the dead coral framework below it, suggesting a high degree of resilience in how frameworkdwelling fauna respond to coral mortality. These data support the assertion that artificial reefs are capable of facilitating the accumulation of a diverse cryptic community, independent of live coral, provided they contain suitably porous crypts.
\end{abstract}

KEY WORDS: Coelobite $\cdot$ Framework $\cdot$ Biodiversity $\cdot$ Porosity $\cdot$ Flow $\cdot$ Coral cover Resale or republication not permitted without written consent of the publisher

\section{INTRODUCTION}

Coral reef cryptofauna (coelobites) are a diverse suite of organisms that live within the cavities and recesses of reef framework structures. In many reef ecosystems, cryptofaunal communities are more species rich (Reaka-Kudla 1997) and comprise greater biomass (Ginsburg 1983, Richter et al. 2001) than both the epibenthos and nekton. Their members include ecologically important trophic groups such as suspension feeders (Richter \& Wunsch 1999, Scheffers et al. 2010), predators (Reaka 1987, Glynn 2006), herbivores (Coen 1988), and detritivores (Rothans \& Miller 1991). Cryptofauna are an important food source for fishes (Bakus 1966, Vivien \& PeyrotClausade 1974), and have been shown to protect 
corals from predators (Glynn 1980) and the harmful effects of coral bleaching (Glynn 1983).

Despite the importance of cryptofauna in coral reef ecosystems, the biological and environmental interactions that affect the life history and distribution of cryptofaunal populations are poorly understood relative to epibenthic reef communities (e.g. Done 1983). Previous studies aimed at determining the effects of substrate structure and porosity on cryptofauna have focused primarily on the associates of live coral. Numerous studies have shown a positive correlation between coral branch density and the abundance of sheltering motile cryptofauna (Kirsteuer 1972, Edwards \& Emberton 1980, Vytopil \& Willis 2001). Similarly, Shirayama \& Horikoshi (1982) found that coral morphology (e.g. massive vs. branching) was an important determinant of the composition of associated motile cryptofaunal communities. Although there appears to be a relationship between the structure of dead coral substrate and cryptofaunal community composition, direct causal connections are often complicated or obscured by extraneous factors (Hutchings \& Weate 1977). In a study of reefassociated invertebrates, many of which exhibited cryptic behaviors, Idjadi \& Edmunds (2006) observed a positive correlation between topographic complexity and overall diversity, but not abundances of these taxa. In extreme cases, however, as when bioerosion has severely limited shelter availability, the abundances and biodiversity of cryptic fishes may be depressed (Glynn 2006).

The effects of flow on cryptic reef populations are also poorly resolved and may be complicated by covariance with other environmental variables such as light and depth (Martindale 1992). Flushing of cryptic habitats may play a crucial role in delivering food to cryptic sessile suspension feeders (Buss \& Jackson 1981) and may facilitate settlement of cryptic biota from the water column. Recent evidence suggests, however, that fast-flow environments can be associated with higher turbidity that may ulti- mately be detrimental to sessile filterfeeding cryptofauna (Scheffers et al. 2010). Additionally, exceptionally high current velocities, such as those experienced during storms, may disturb or even overturn cryptic shelters, to the detriment of their occupants (Gischler \& Ginsburg 1996).

There is some evidence that live coral substrates may support distinct species assemblages and elevated motile cryptofaunal biomass relative to dead coral substrates (Coles 1980, Preston \& Doherty 1990, 1994, Enochs \& Hockensmith 2009). Although live coral tissues may inhibit the penetration of endolithic bioeroders (Hutchings 1985, Fonseca et al. 2006) and deter epilithic fauna sensitive to cnidae and mucus production (Kirsteuer 1969), coral mucus may be beneficial to other members of the cryptofauna. Coral mucus, adhering organics, and other metabolic products of the coral provide an important source of nutrition to cryptofauna residing within live corals and reef sediments (McCloskey 1970, Wild et al. 2004). Enhanced food supply near live coral may explain the observed elevation of symbiont biomass in these areas (Stimson 1990). Despite the putative relationship between cryptofaunal food supply and the presence of live coral, Idjadi \& Edmunds (2006) found no significant relationship between percent coral cover and the abundance of reef-associated invertebrates. It is not clear, therefore, whether living coral truly elevates the biomass of metazoans inhabiting surrounding frameworks.

Replicate sampling of cryptofauna across environmental gradients is difficult and often impractical due to the hidden nature of cryptic biota, their close association with ecologically sensitive structural taxa, and their high variability across different reef microhabitats. Researchers have therefore employed artificial substrate structures made of either coral rubble (Peyrot-Clausade 1977, Zimmerman \& Martin 2004, Glynn 2006, Valles et al. 2006, Takada et al. 2007, 2008) or man-made materials (Zimmerman \& Martin 2004) to understand the ecology of motile coral reef cryptofauna. These techniques have allowed researchers to successfully study patterns of colonization (Peyrot-Clausade 1977, Glynn 2006, Valles et al. 2006) and succession of cryptic biota (Peyrot-Clausade 1977, Takada et al. 2007), as well as the role of sediment in structuring cryptofaunal community composition (Takada et al. 2008).

The effects of flow, coral cover, and porosity have been shown to have significant impacts on many groups of reef biota (e.g. flow on coral cover, Geister 1977; coral cover on fishes, Bell \& Galzin 1984, Jones et al. 2004; and porosity on fishes, Holbrook et al. 2002). We present the first study to experimentally investigate the effects of these parameters on communities of cryptic reef organisms.

\section{MATERIALS AND METHODS}

Two $20 \times 20 \mathrm{~m}$ plots were located $\sim 400 \mathrm{~m}$ apart at Playa Larga Reef $\left(8^{\circ} 38^{\prime} 0.75^{\prime \prime} \mathrm{N}, 79^{\circ} 1^{\prime} 47.90^{\prime \prime} \mathrm{W}\right)$, Isla Contadora, Pearl Islands, Panamá (Fig. 1). The exposed northern site (Fig. 1a) was observed to experience higher water velocities than the southern site 
(Fig. 1b). Paired mechanical flow meters (General Oceanics Model 2030R) were deployed at the SW corner of both sites $<1 \mathrm{~m}$ above the reef surface for $\sim 24 \mathrm{~h}$ periods to corroborate this observation. Mea-

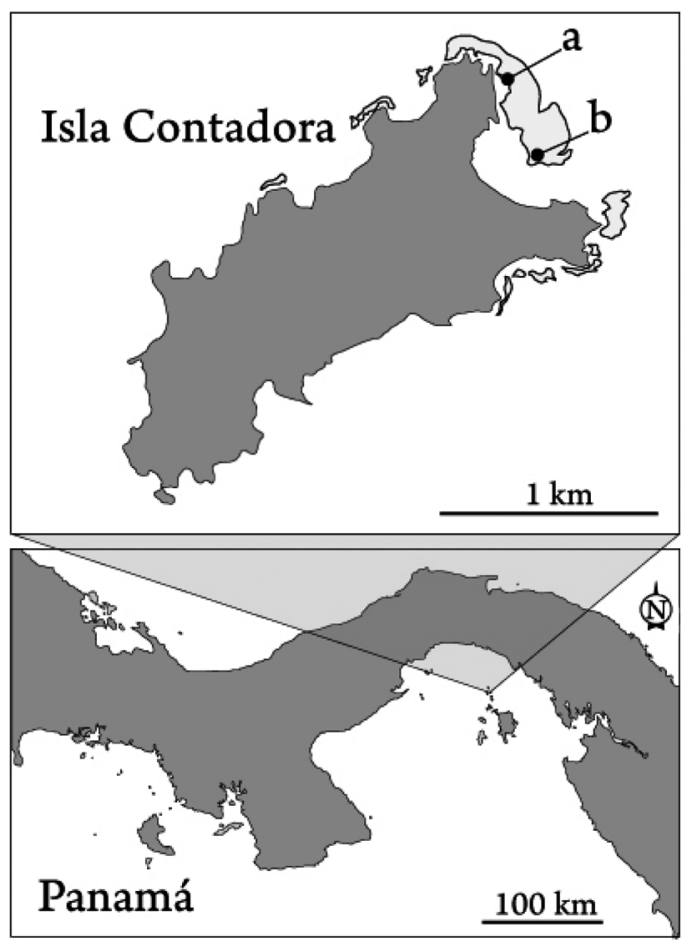

Fig. 1. Isla Contadora in the Pacific Gulf of Panamá $\left(8^{\circ} 38^{\prime} 0.75^{\prime \prime} \mathrm{N}, 79^{\circ} 1^{\prime} 47.90^{\prime \prime} \mathrm{W}\right)$. Location of fast- (a) and slow-flow (b) study sites. Light grey shaded features surrounding Isla Contadora are reef formations

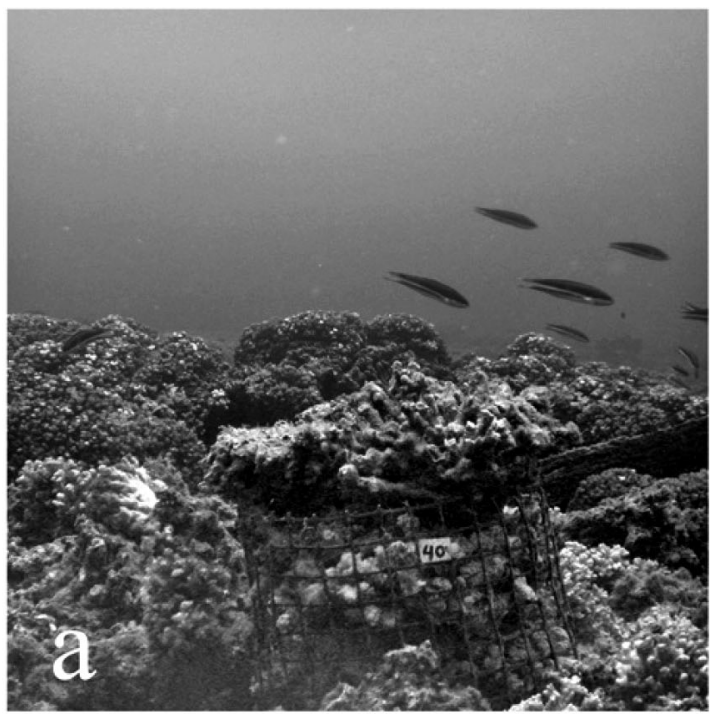

surements were made during a period ranging from $10 \mathrm{~d}$ before to $7 \mathrm{~d}$ after new moon. Water flow was $\sim 11$ times greater at the fast-flow site $\left(\bar{X}=13.4 \mathrm{~cm} \mathrm{~s}^{-1}\right.$, $\mathrm{SD}=1.3)$ compared to the slow-flow site $(\bar{x}=1.2 \mathrm{~cm}$ $\mathrm{s}^{-1}, \mathrm{SD}=0.3$ ), when averaged over a $\sim 24 \mathrm{~h}$ period. Both sites were $\sim 1.5 \mathrm{~m}$ deep at low tide, though the typical tidal amplitude in the Gulf of Panamá ranges from 4 to $5 \mathrm{~m}$. Coral cover within each site was determined from five $0.25 \mathrm{~m}^{2}$ photoquadrats taken every $4 \mathrm{~m}$ along 4 parallel transects placed $5 \mathrm{~m}$ apart $(\mathrm{n}=20$ quadrats site ${ }^{-1}$ ). Percent cover of live coral was high, but variable (low-flow site $=56.0 \%, \mathrm{SD}=16.5$; fastflow site $=38.3 \%$, SD $=21.35$ ), consisting primarily of Pocillopora damicornis. Artificial reef framework units (ARFs) were constructed from a plastic mesh with openings of $\sim 2.4 \times 2.1 \mathrm{~cm}$. Individual ARF units were held together with plastic cable ties to form open-topped cylinders, roughly $23 \mathrm{~cm}$ high and $28 \mathrm{~cm}$ in diameter (Fig. 2). Each ARF 'basket' was tagged and randomly assigned treatment combinations of flow (fast vs. slow), porosity (high vs. low), and cover (live vs. dead coral), in a fully crossed design. To obtain ARF substrates, unconsolidated dead $P$. damicornis rubble was removed from disturbed sections of the Playa Larga reef, cleaned of large sessile macrobiota, and allowed to sun-dry for $\sim 1 \mathrm{wk}$. Rubble ranged in length from roughly 1 to $10 \mathrm{~cm}$, with larger fragments exhibiting greater structural complexity and branching. High- and lowporosity treatments were assembled by completely filling each ARF with either large or small pieces of coral rubble, respectively. Because of the size and

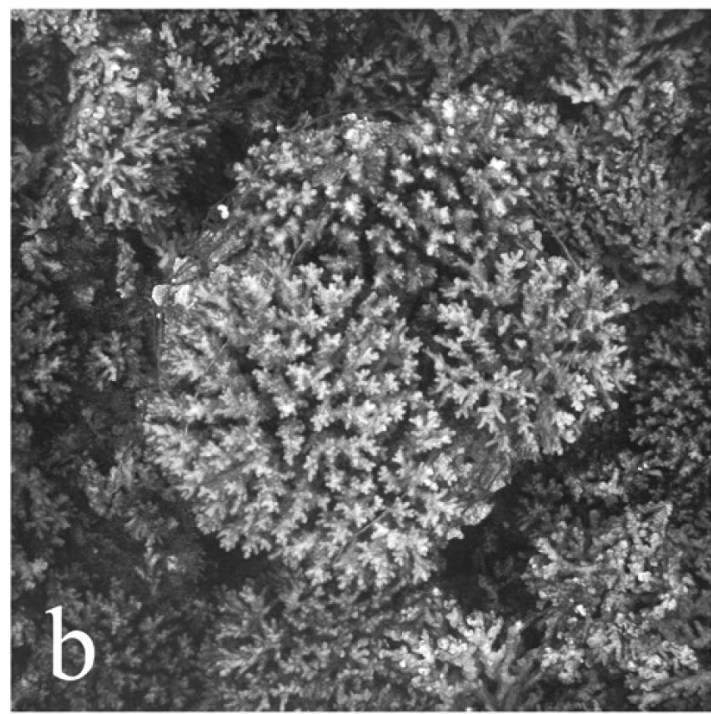

Fig. 2. (a) Side view of artificial reef frame (ARF) with a dead coral treatment. (b) Top-down view of an ARF unit covered with a live coral treatment, illustrating the similarity to surrounding reef environments 
complexity of large rubble fragments, ARF units composed of large rubble pieces were less densely packed than those containing small, low-complexity rubble. Large rubble ARFs therefore contained volumetrically less rubble material, resulting in a greater amount of void space and higher porosity than those filled with small rubble. The volume of rubble within each ARF was measured a priori using volumetric water displacement, and the rubble composition of each ARF was adjusted so that replicate ARFs within each treatment were consistent prior to deployment.

Twenty ARFs, including 10 replicates of each porosity treatment, were placed at both fast- and slow-flow sites (Fig. 1). Within each site, ARFs were positioned according to randomly selected $x$ - and $y$-coordinates across a $20 \times 20 \mathrm{~m}$ grid and secured to rebar hammered into the substrate. Each ARF unit was randomly assigned to live or dead coral cover treatments, and large fragments of either live or dead Pocillopora damicornis, collected outside of the experimental plots, were affixed to the upper surface of the ARFs $\left(\sim 620 \mathrm{~cm}^{2}\right)$ with heavy-test monofilament line. During the course of the experiment, physical disturbance and partial removal of cover treatments was observed on 6 of the 40 ARF replicates; however, of these replicates, live and dead coral cover was still sufficient to include them in further analysis. Post hoc analysis of the ARF unit volumes between sites revealed a marginally significant difference ( $t$-test, 2 tails, $\mathrm{p}=0.04$ ) in low-porosity treatments despite the overall high similarity of the ARFs $(\bar{x}=76.2 \%$, $\mathrm{SD}=1.7 ; \bar{x}=58.2 \%, \mathrm{SD}=1.3$, high and low porosity, respectively). Although natural variation in the volume of the ARF container (due to its flexibility) likely obscured the observed $2.66 \%$ lower mean porosity at the slow-flow site, the difference between sites was likely due to a single anomalously lowporosity replicate at the slow-flow site. This outlier was excluded from future statistical tests (ANOVA and PERMANOVA), in order to eliminate potential bias.

ARF units were deployed on September 22, 2008 and removed after $\sim 2$ mo in situ (collected between November 26 and December 2). During collection, live and dead cover treatments were removed underwater and returned to the reef. ARF units were then carefully placed in plastic buckets and quickly brought to the surface. Few metazoans were observed to escape during ARF collection, and those that did were noted. Seawater and ARF rubble was separated over a $2 \mathrm{~mm}$ mesh filter and all cryptofauna were removed from the surface of framework materials with forceps. Collected specimens were preserved in $70 \%$ EtOH.

Individual organisms were counted and identified to the lowest possible taxonomic level. Operational taxonomic units (OTUs), used for the calculation of diversity indices and multivariate analyses, are herein defined as unique taxonomic groups identified to the lowest possible level. Wet weights were recorded using an analytical balance and converted to ash-free dry weights (AFDW) according to Table S1 in the supplement at www.int-res.com/ articles/suppl/m438p105_supp.pdf. Specimens were assigned to trophic groups according to Table S2 in the supplement (abbreviations for those groups are: $\mathrm{CG}=$ carnivorous grazer $\mathrm{CM}=$ carnivorous multiple strategies; $\mathrm{CP}=$ carnivorous predator; $\mathrm{DD}=$ detritivorous deposit feeder; HG = herbivorous grazer; $\mathrm{OG}=$ omnivorous grazer; $\mathrm{OO}=$ omnivorous opportunistic $;$ $\mathrm{SU}=$ suspension feeder).

Treatment-specific abundance and biomass data for each taxon were compiled into 2 OTU-sample data matrices using MATLAB v7.0.1. Data matrices were loaded into the Plymouth Routines in Multivariate Ecological Research (PRIMER-E) with the PERMANOVA+ software package (Anderson et al. 2008). Two sub-matrices were formed from both the abundance and biomass data matrices by either filtering out non-OTUs or grouping all taxa into trophic groups irrespective of OTU status. Total abundances and biomass, 3 biodiversity metrics (OTU richness, Fisher's $\alpha$, Shannon's $\left.H^{\prime}\left[\log _{\mathrm{e}}\right]\right)$, and percent trophic group composition were calculated for each ARF. Univariate sample parameters were analyzed with SPSS v17.0 using a 3-way general linear model analysis of variance (ANOVA). Biomass data were $\log _{10}$ transformed, and percent trophic group data were arcsine transformed in order to comply with the constraints of homoscedasticity and normality inherent in ANOVA.

Bray-Curtis similarity matrices were constructed from abundance and biomass data matrices after square-root transformation. Two-dimensional ordinations were constructed from OTU-sample abundance and biomass matrices using non-metric multidimensional scaling (nMDS), and dendrograms were created from group-averaged cluster analysis. In order to clearly differentiate treatments along axes explaining known amounts of variability, treatment centroids were also ordinated in 2-dimensional space using principle coordinate analysis (PCO) of OTU abundance and biomass data. The use of PCO in conjunction with nMDS clearly highlights the overall trends in the dataset which may be partially ob- 
scured by the data variance expressed in the nMDS ordination. The dimensionality of untransformed abundance and biomass data was reduced by consolidating taxa into trophic groups. The resulting data were square-root transformed and ordinated using PCO. Trophic group vectors were superimposed onto the Euclidian space of the PCO plots in order to investigate their linear (Pearson) correlation with the ordination axes. Permutational analysis of variance (PERMANOVA) was used to test the significance of the 3 treatments and their interactions on the multivariate datasets without the constraints of homoscedasticity and normality inherent in the MANOVA test (Anderson 2001). Pseudo F-ratios were computed from 99999 permutations.

\section{RESULTS}

\section{Taxa collected}

A total of 180 OTUs were recognized, 121 of which were classified to the species level. These cryptofauna belonged to 6 phyla, 10 classes, 22 orders, 33 superfamilies, 83 families, and 118 unique genera. Of the 11309 specimens collected, 10297 individuals were assigned OTU status. The remaining 1012 individuals were included in abundance and biomass analyses, but were not used to compute diversity indices. Palaemonella spp., which accounted for $11.75 \%$ of all individuals collected, was the most abundant OTU. The 25 most abundant OTUs accounted for $87.37 \%$ of all cryptofauna identified in the present study (Fig. 3) and included 14 OTUs belonging to Crustacea, 5 Gastropoda, 2 Holothuroidea, 2 Ophiuroidea, and 2 Polychaeta (Table S2).

\section{Porosity}

Low-porosity frameworks had greater abundances and biomass of cryptofauna compared to highporosity frameworks (Tables $1 \& 2$ ). Species richness was higher in the low-porosity treatments, but the other 2 diversity indices used in the present study $\left(\alpha, H^{\prime}\right)$ indicated that there was greater biodiversity within high-porosity treatments.

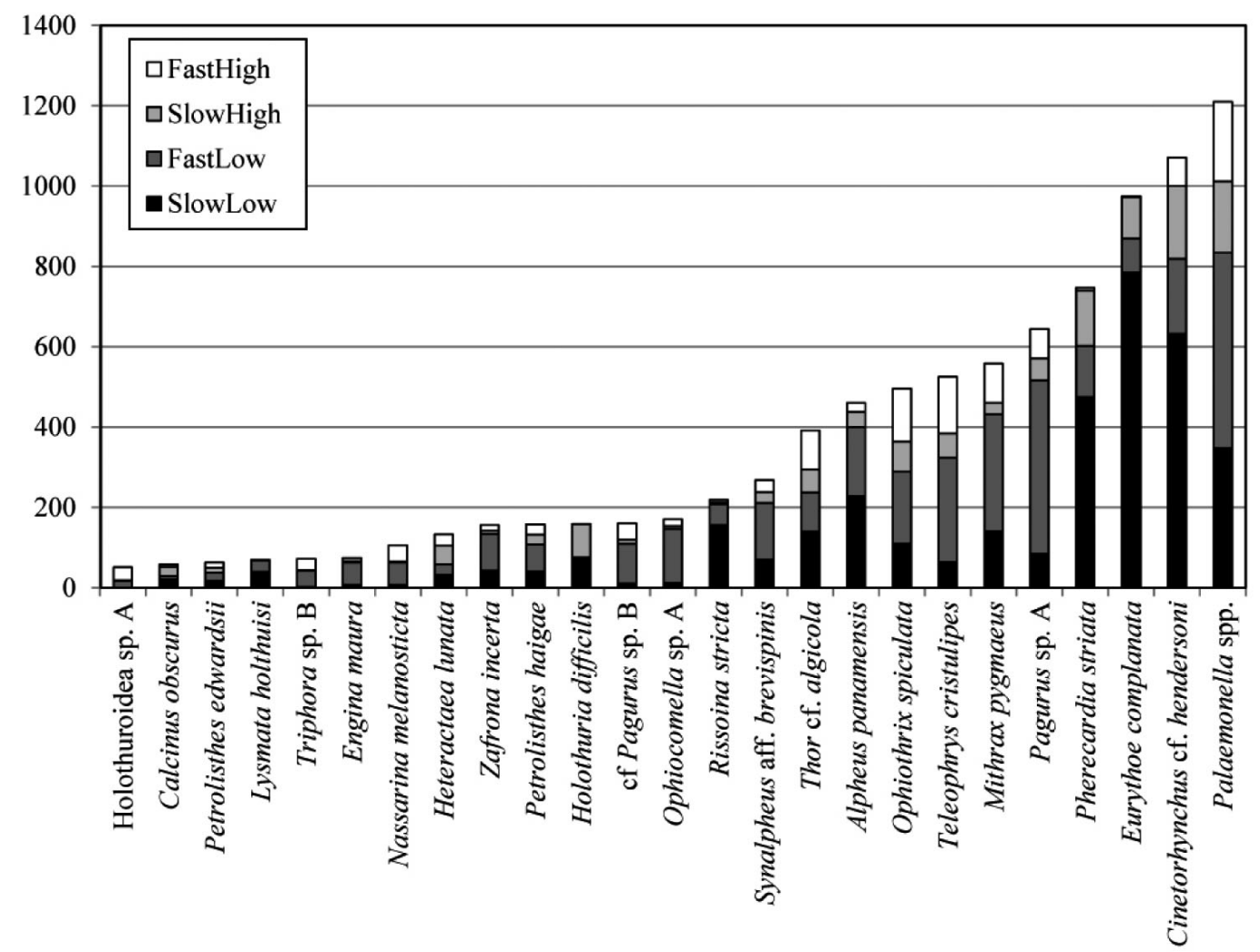

Fig. 3. Number of individuals collected in each of the 25 most abundant operational taxonomic units from each of 4 unique combinations of flow and porosity treatments 


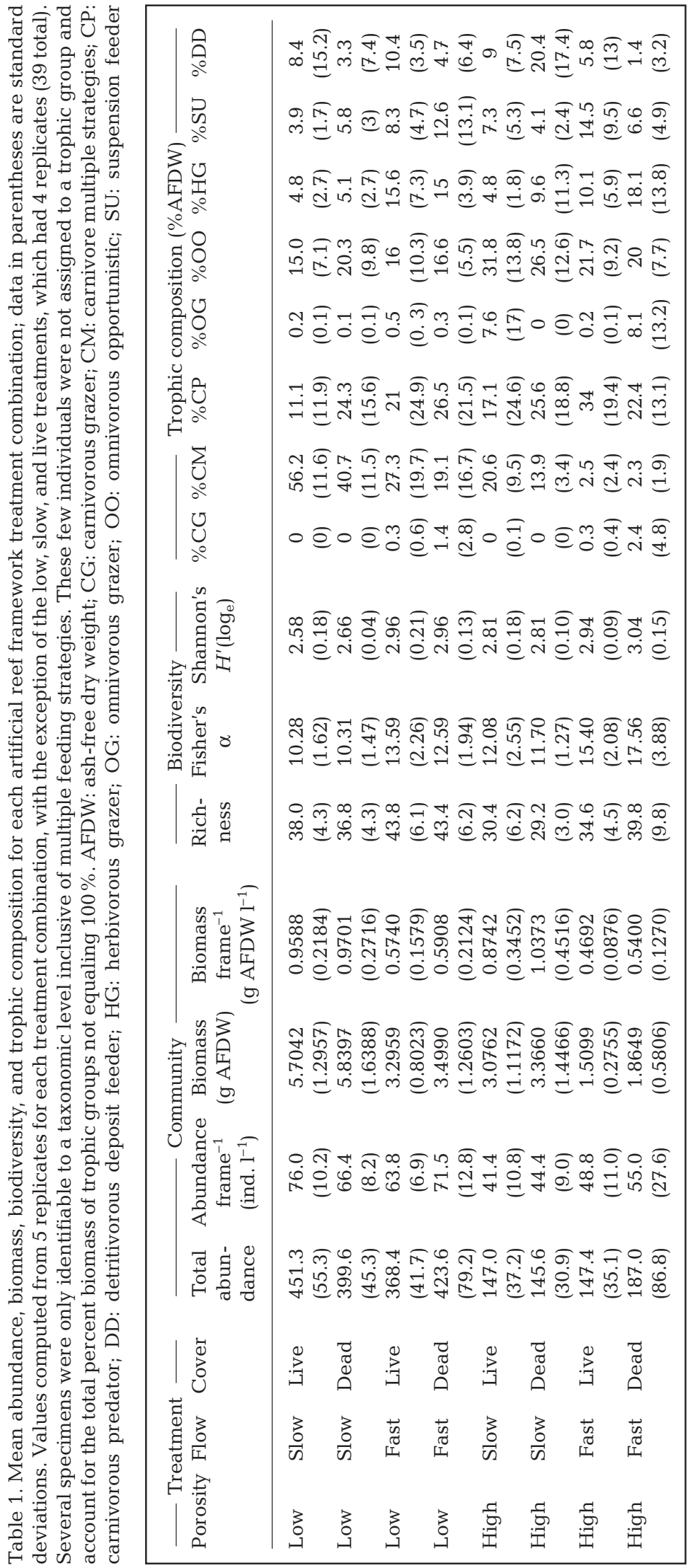

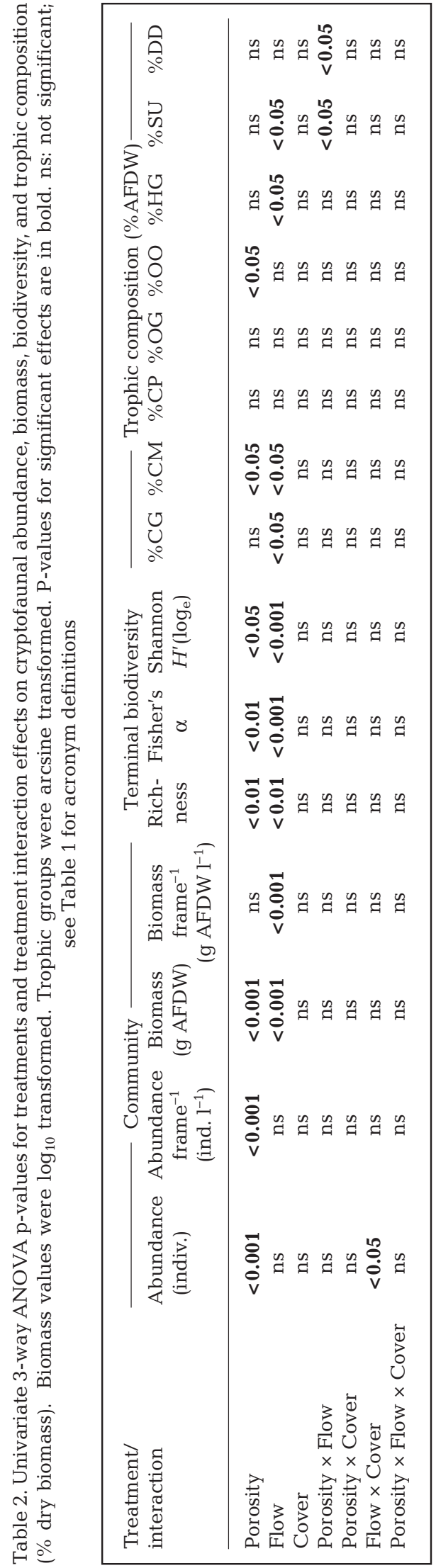


PERMANOVA revealed that, in addition to influencing total community parameters, porosity significantly affected the relative abundances and biomass of cryptofaunal OTUs and trophic groups (Table 3).

Table 3. PERMANOVA p-values for treatment and interaction effects on the abundance and biomass of species and trophic groups. Analysis for species based on operational taxonomic units (OTUs) only. Analysis for guilds based on all taxa assigned to guilds, regardless of OTU status. All data sets were square-root transformed, and analysis was based on symmetrical Bray-Curtis similarity matrices. P-values were based on F-ratios constructed from 99999 permutations. Significant results are indicated in bold. ns: not significant

\begin{tabular}{|c|c|c|c|c|}
\hline \multirow[t]{2}{*}{ Treatment/interaction } & \multicolumn{2}{|c|}{ - Species — } & \multicolumn{2}{|c|}{ — Trophic groups } \\
\hline & Abundance & Biomass & Abundance & Biomass \\
\hline Porosity & $<0.0001$ & $<0.0001$ & $<0.0001$ & $<0.0001$ \\
\hline Flow & $<0.0001$ & $<0.0001$ & $<0.0001$ & $<0.0001$ \\
\hline Cover & ns & ns & ns & ns \\
\hline Porosity $\times$ Flow & $<0.0001$ & $<0.0001$ & $<0.0001$ & $<0.01$ \\
\hline Porosity $\times$ Cover & ns & ns & ns & ns \\
\hline Flow $\times$ Cover & ns & ns & $\mathrm{ns}$ & ns \\
\hline Porosity $\times$ Flow $\times$ Cover & $\mathrm{ns}$ & ns & ns & ns \\
\hline
\end{tabular}

These patterns were also apparent in the nMDS and cluster analyses (Fig. 4) as well as PCO plots of treatment centroids (Fig. 5), which each showed strong differentiation between porosity treatments. Communities associated with low-porosity ARFs were more similar to each other than those within high-porosity treatments (Fig. 4).

Although PCO of trophic group abundances shows clear differentiation between porosity treatments, the ordination of the biomass data is more difficult to interpret, likely due to the inherent variability in this type of data (Fig. 6). There were positive linear correlations between several trophic groups' abundances and the low-porosity ARFs (Fig. 6). This is not surprising considering the higher total abundances of cryptofauna observed in these treatments; however, the especially strong correlation of

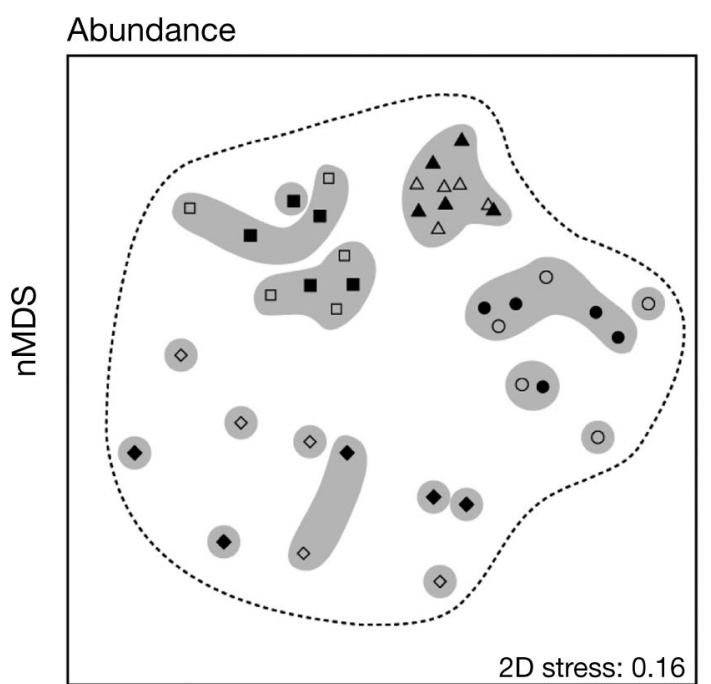

Biomass
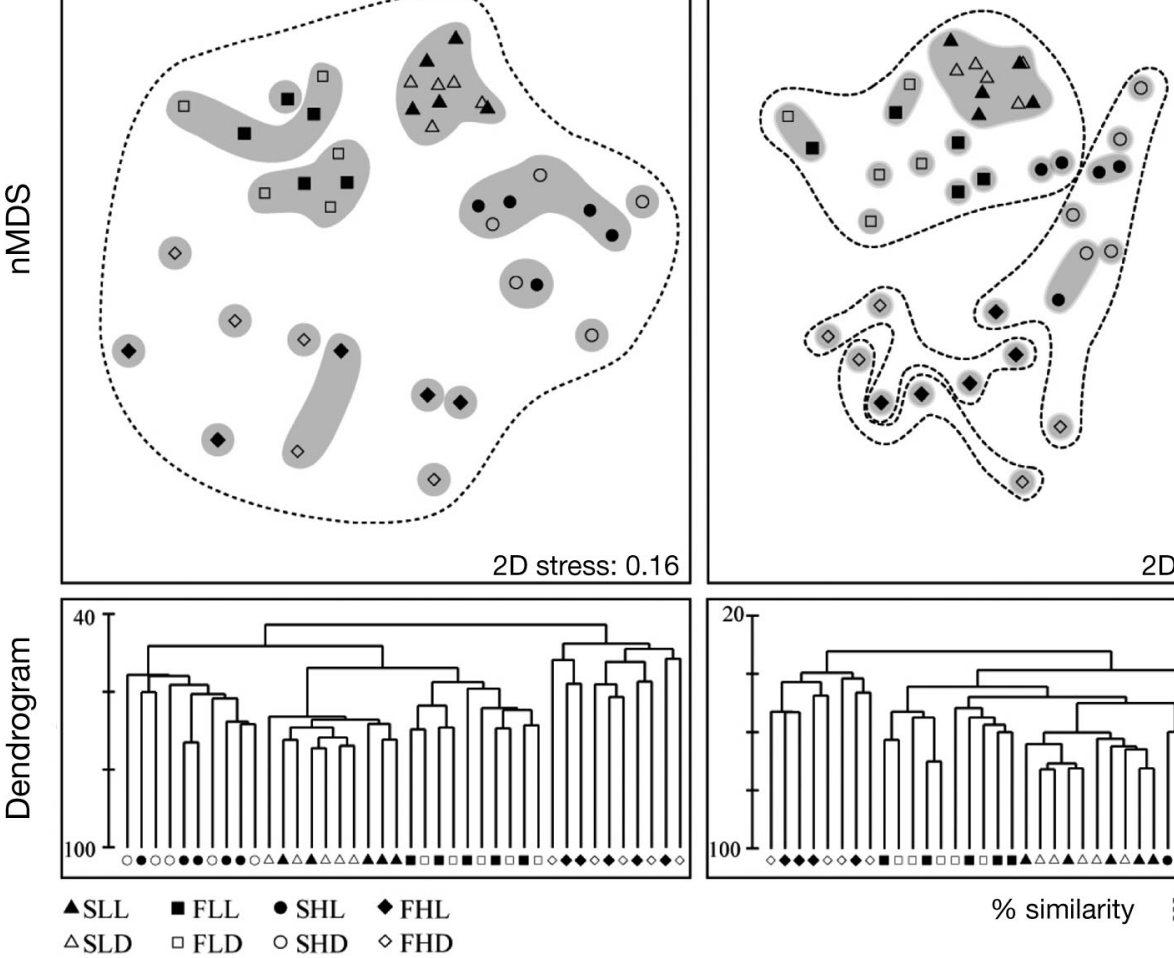

2D stress: 0.18

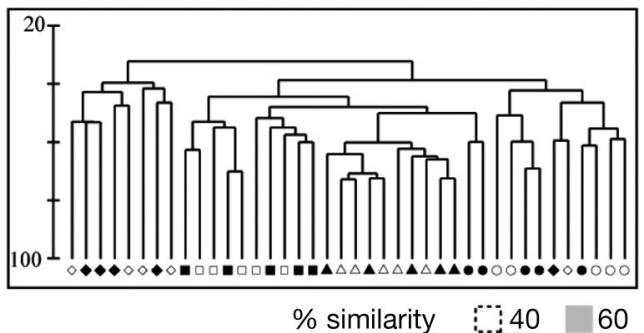

Fig. 4. Two-dimensional non-metric multidimensional scaling (nMDS) plots of cryptofaunal operational taxonomic unit abundance (stress $=0.16$ ) and biomass (stress $=0.18$ ), with corresponding dendrograms constructed from Bray-Curtis similarity. Dashed enclosures and shaded regions in the nMDS plots represent 40 and $60 \%$ similarity, respectively. In the key, the letters represent (1) current (S: slow; F: fast), (2) porosity (L: low; H: high), and (3) coral cover (L: live; D: dead). All data were squareroot transformed 

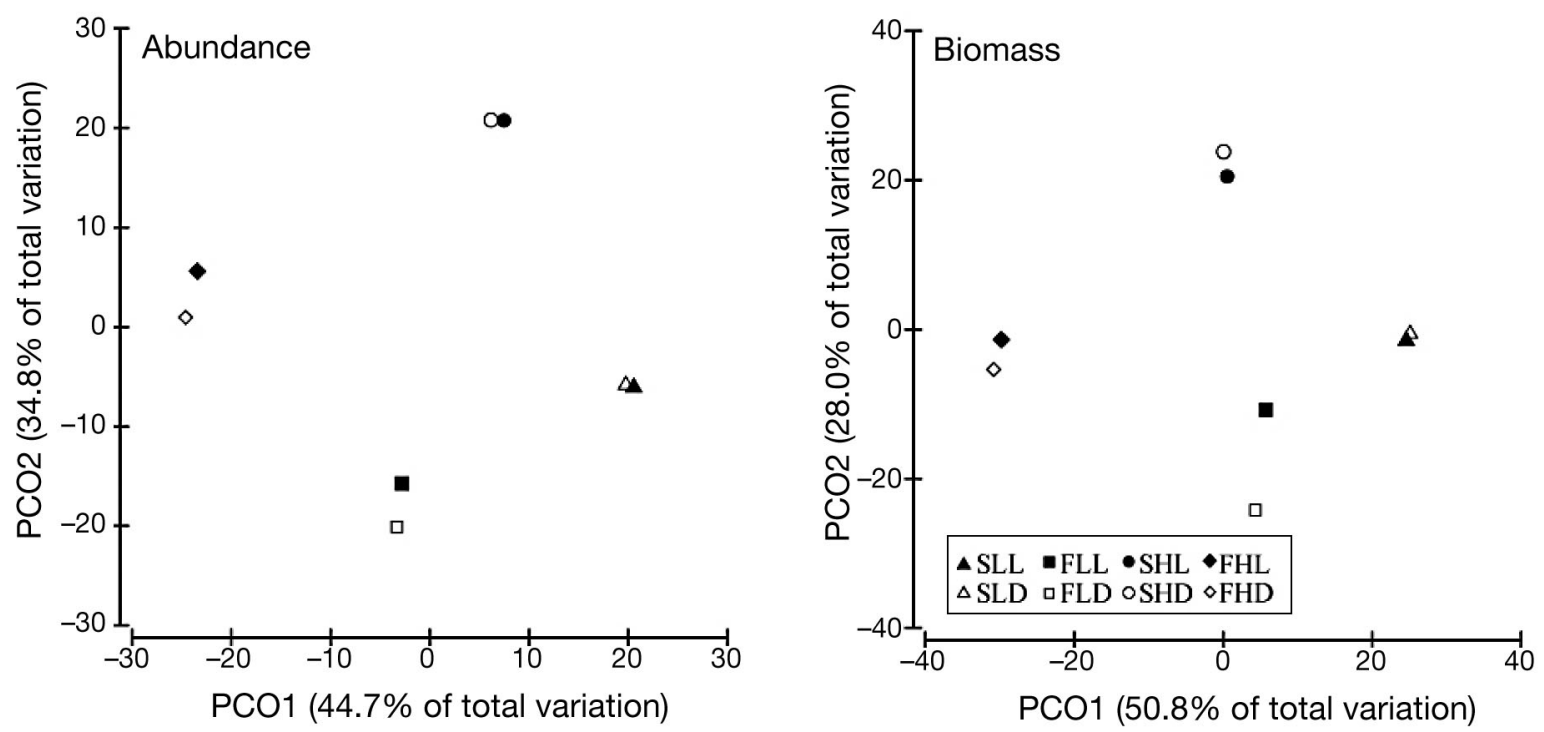

Fig. 5. Principal coordinate analysis (PCO) plots of treatment centroids for cryptofaunal operational taxonomic unit biomass and abundance. Abundance and biomass plots explain 79.5 and $78.8 \%$ of the variation, respectively. Key legend as in Fig. 4 . Data were square-root transformed and distances are based on Bray-Curtis similarity
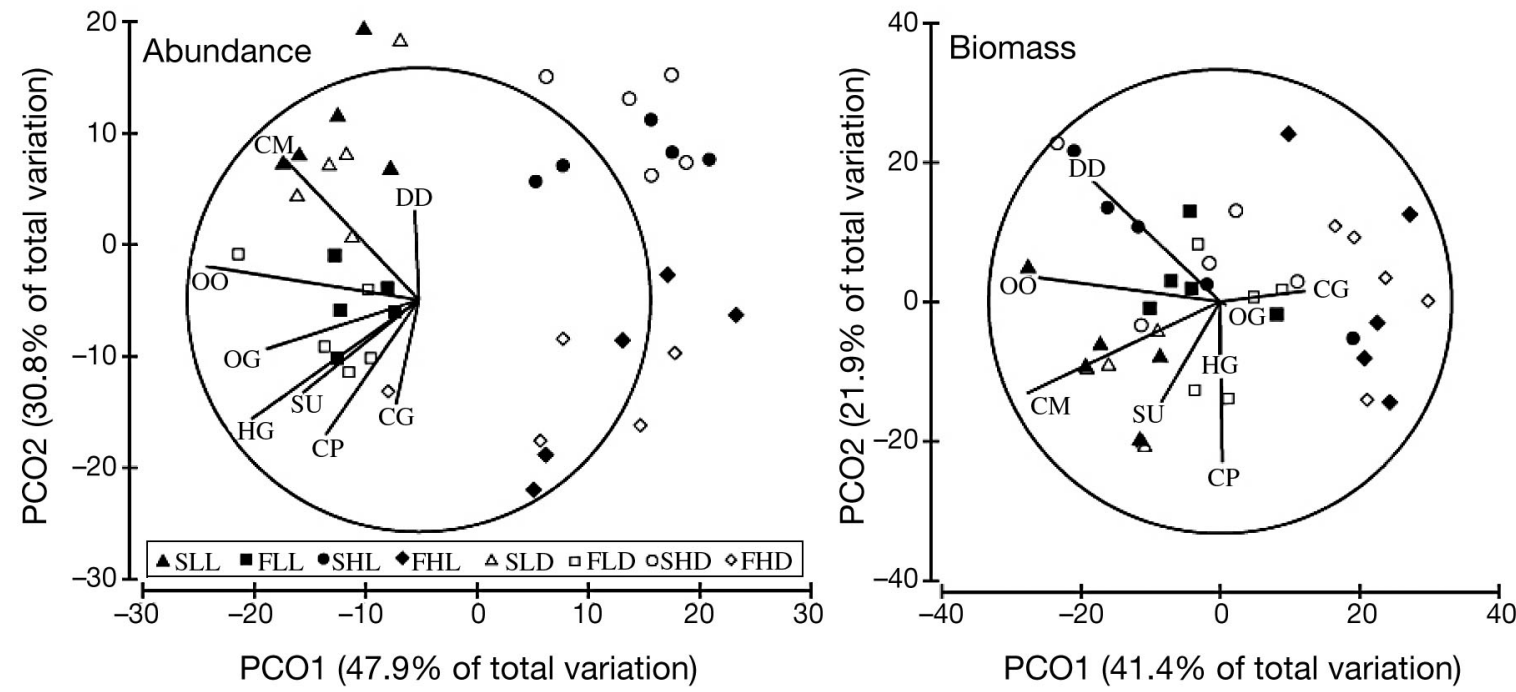

Fig. 6. Principal coordinate analysis (PCO) plots of the biomass and abundance of cryptofaunal trophic groups by treatment. Abundance and biomass plots explain 78.7 and $63.3 \%$ of the variation, respectively. Vector overlays represent linear Pearson correlations between the square-root-transformed biomass or abundance of a given trophic group and the ordination axes (Acronyms see Table 1). Vector length is proportional to the degree of correlation. Length equal to the radius of the circle corresponds to a correlation coefficient of 1.0. Key legend as in Fig. 4. Data were square-root transformed and distances are based on Bray-Curtis similarity

$\mathrm{CM}$ and $\mathrm{OO}$ feeding groups (Fig. 6), coupled with their concomitant rise in prevalence in low-porosity treatments (Table 2), suggests that these groups are especially sensitive to substrate porosity. With respect to the CM trophic group, this trend is primarily due to the distribution of the amphinomid polychaetes Pherecardia striata and Eurythoe complanata (Fig. 3).
Flow

Both mean biomass and biomass per liter frameworks were significantly greater in the slow-flow environment; however, biodiversity was higher in fast-flow treatments (Tables $1 \& 2$ ). Total OTU abundance and abundance per liter substrate were not significantly affected by flow. As with porosity, PER- 
MANOVA indicated significant effects of flow on the community composition and the distribution of biomass among both OTUs and trophic groups (Table 3). There was strong clustering of flow treatments in the nMDS (Fig. 4) and clear differentiation between slow- and fast-flow treatments in both the PCO plot of treatment centroids (Fig. 5) and the PCO plot of trophic group abundances (Fig. 6).

$\mathrm{CM}$ accounted for a significantly greater percentage of community biomass in slow-flow treatments, while CG, HG, and SU biomass were proportionally more important under fast-flow conditions (Table 2). These trends were corroborated by correlations between flow treatments and trophic group vectors in the abundance plot of Fig. 6. Percent DD biomass did not differ significantly across flow treatments, although there was a significant interaction effect of porosity and flow for this trophic group (Table 2). PCO of trophic group abundances, however, showed that DD was strongly correlated with flow, independent of porosity. This correlation is largely due to the distribution of the numerically dominant Holothuria difficilis, which was conspicuously absent from the high-flow environment (Fig. 3).

\section{Interaction of porosity and flow}

There were highly significant flow/porosity interaction effects on both multivariate OTU and trophic group abundances and biomass (Table 3 ). These patterns were not observed for any of the univariate community parameters, with the exception of \%SU and \%DD (Table 2). Interaction effects are, therefore, primarily related to community composition, rather than the combined abundance or biomass of all cryptofaunal associates.

Evidence for the unique structure of cryptofaunal communities under combinations of flow and porosity treatments is apparent in the strong clustering of replicates as well as in the clear differentiation of permutations between these 2 treatments in the nMDS ordinations (Fig. 4). In the PCO plots of biomass and abundance, slow-flow/low-porosity and fast-flow/high-porosity treatments are clearly separated along PC1, which explains the greatest amount of variation in the plot (Fig. 5). Fast-flow/low-porosity and slow-flow/high-porosity treatments are poorly differentiated along PC1 and instead show separation along $\mathrm{PC} 2$.

The uniqueness of cryptofaunal communities associated with the fast-flow/high-porosity treatment is highlighted in the nMDS plots and corresponding dendrograms. Replicates within this treatment combination are clearly differentiated from all other combinations of flow and porosity. There is, however, higher variability among fast-flow/high-porosity replicates, as reflected by the wide separation of these cryptofaunal communities in the Euclidian space of the nMDS plot of abundance and, to a lesser extent, biomass. The PCO plot of trophic group biomass also indicates that cryptofauna living in open and fast-flow environments form unique communities (Fig. 6). In this plot, PCO1, explaining $41.4 \%$ of total variation, shows differentiation of the fastflow/high-porosity treatment, while the remaining 3 flow/porosity treatment combinations are poorly separated in either PCO1 or PCO2.

\section{Coral cover}

Cover treatments did not significantly affect any of the measured community statistics or terminal biodiversity metrics (Table 2). No significant effect of coral was observed in the PERMANOVA (Table 3), and there was little differentiation between cover treatments in the nMDS (Fig. 4) or PCO plots (Figs. 5 \& 6). Together, these data suggest that cover did not influence relative species abundances within the ARF units. There was a marginally significant interaction effect of cover and flow on total cryptofaunal abundance (Table 2), but this was likely a Type I error (false rejection of the null), as the effects of both flow and cover were insignificant.

\section{DISCUSSION}

\section{Determinants of community composition}

This is the first study to experimentally examine the distribution of the motile cryptofauna across multiple environmental conditions. Recent work has highlighted the important roles that cryptic communities play in reef ecosystem function (e.g. Richter \& Wunsch 1999, van Duyl et al. 2005, de Goeij \& van Duyl 2007, Scheffers et al. 2010, Glynn \& Enochs 2011), but the majority of these studies have focused on sessile cryptofauna.

Framework porosity was an important determinant of community composition, and cryptofauna were most abundant in low-porosity treatments. This effect was likely due to the higher volume of rubble and, therefore, greater habitable surface area within the low-porosity ARF treatments. The standardiza- 
tion of community parameters to substrate volume provides a metric that is applicable to the loss of framework complexity, as it is independent of the quantity of substrate within each treatment. Indeed, cryptofaunal abundances (but not biomass) were significantly higher per volume substrate in the lowporosity treatments (Tables $1 \& 2$ ), suggesting that, at intermediate levels, erosion of large intact framework fragments may lead to increases in cryptofaunal abundances.

The abundance of cryptofauna may be more closely related to surface area than to volume (Abele \& Patton 1976, Coles 1980). Thus, the greater surface area of the low-porosity treatments may be responsible for the elevated abundances independent of volume. Vytopil \& Willis (2001) explored the relationship between habitable surface area and volume in their investigation of cryptofauna inhabiting different species of living acroporid corals. Acropora species exhibiting greater surface area per colony volume sheltered more abundant and more species-rich communities of cryptofauna. Neither surface area nor interbranch volume, however, were independently correlated with abundances or species richness. In contrast, Coles (1980) found that surface area was the most important determinant of cryptofaunal community abundances and species richness on both live and dead coral substrates. Further inquiry is therefore necessary to determine the relationship between dead framework surface area, volume, and cryptofaunal abundances, though accurate surface area measurements of structurally complex interdigitating rubble fragments are difficult.

Elevated densities of cryptofauna in low-porosity crypts may have been the result of ecological processes unique to these habitats. For example, lowporosity framework may simply offer greater protection from predators than highly porous habitats (e.g. Vytopil \& Willis 2001). Cryptofauna, which often lack effective antipredatory morphologies, are likely restricted to these environments because of the high predation pressures on exposed reef surfaces (Bakus 1966).

The elevated species richness in the low-porosity treatment may be due to higher abundances in lowporosity ARFs, resulting in greater numbers of observed species. Diversity indices that incorporate evenness (i.e. $\alpha, H^{\prime}$ ) provide a less biased comparison between the 2 porosity treatments and are therefore better metrics of true biodiversity. These indices revealed higher diversity within high-porosity habitats, a pattern which may be attributed to various ecological processes. For example, reduced preda- tion pressure may allow the proliferation of competitively dominant species in low-porosity crypts (Hutchinson 1941, Levin \& Paine 1974) or small void sizes in these habitats may restrict the movement/ occupation of larger/less agile taxa. Alternatively, niche diversity may be greater in high-porosity crypts (Hutchinson 1957, Leviten \& Kohn 1980). More open environments allow greater light penetration and more access to suspended matter in the water column. Light and the presence of photosynthetic organisms are known to influence the composition of sessile cryptofaunal communities (e.g. Cinelli et al. 1977, Wunsch et al. 2000) and correlate positively with the abundance of motile cryptic herbivores (Peyrot-Clausade 1989). Conversely, Navas and colleagues (1998) suggest that in some high light situations, algae may out-compete sessile taxa and thereby reduce overall biodiversity. In this study, however, algal cover was not observed to reach such an extreme and therefore was likely not a negative influence on community diversity.

Slow-flow environments are more conducive to the development and accumulation of cryptofaunal biomass than fast-flow environments. Abundances, however, were not significantly affected by flow, suggesting that over short time periods $(\sim 2 \mathrm{mo})$ flow may significantly influence mean body size of cryptofauna, but not the total number of individuals. Areas of low water flow often have high deposition or retention of sediment and organic matter (Nowell \& Jumars 1984). These organic deposits and bacteriarich sediments are an important food source to diverse deposit-feeding taxa (Glynn \& Enochs 2011). As a result, deposit feeders (DD) should have greater numbers and/or biomass in areas that experience less turbulence. Indeed, there was correlation between the DD trophic group and slow-flow treatments in the PCO plot of abundance, yet \%DD biomass was not significantly greater in the slow-flow treatments of the present study. This suggests that some other factor, perhaps increased predation where water movement is reduced, controls the build-up of this group's biomass where their food source is most readily available.

Greater cryptofaunal abundances in slow-flow environments could be the result of current- or waverelated disturbance limiting the numbers of these taxa in fast-flow environments (Gischler \& Ginsburg 1996). It is unlikely that physical disturbance of the substrate was an important factor in this experiment due to the consolidated nature of the experimental units. In natural environments, however, substrate mobility may disturb cryptofauna, which could result 
in even stronger effects of flow than those observed in the present study.

Decreases in herbivorous taxa in slow-flow treatments may be due to increased sediment accumulation, as sedimentation can inhibit algal growth (Airoldi \& Virgilio 1998). Furthermore, lower proportions of suspension feeders in the slow-flow environments may be a result of limited food availability (Buss \& Jackson 1981) or due to sediments clogging the filter apparatus (Rhoads \& Young 1970). Scheffers et al. (2010), however, observed positive correlation between flow and turbidity in framework cavities and hypothesized that elevated turbidity restricted filter-feeding cryptofauna in fast-flow environments. Though the fauna in the Scheffers et al. (2010) study are sessile and inhabit reef cavities that are structurally distinct from those in the present study, the apparent incongruity of patterns observed in their study with those observed in ours highlights the complexity of the relationship between flow, sediments, and the population structure of suspension-feeding cryptofauna. Further study is therefore necessary to determine taxon-specific tolerances and tease out the relationships between cavity structure, sediments, and flow.

Despite lower total abundances, cryptofaunal communities were more diverse in fast-flow environments. In these areas, there is likely a higher probability of settlement by rare species because the benthos experiences a greater volume of water transport across its surfaces (Palardy \& Witman 2011). Alternatively, greater flushing may have led to an increased abundance of sessile flora and fauna that may have otherwise been intolerant to the elevated sedimentation associated with slow-flow environments (Nowell \& Jumars 1984). Greater quantities and varieties of epilithic flora and fauna could have, in turn, supported a higher diversity of motile cryptofauna (Hutchinson 1957, Leviten \& Kohn 1980). Although the effects of these processes are difficult to discern from the biomass PCO plot, the ordination of abundance data reveals that 5 trophic groups are positively correlated with fast-flow environments as opposed to only 3 groups that are positively correlated with slow flow. These results suggest that many trophic groups benefit from fast-flow conditions.

The interaction effects observed in the present study may be due to the inherent interrelatedness of porosity and flow in coral reef ecosystems. For example, the high density of low-porosity frameworks likely slows internal water flow relative to the surrounding environments. The occupants of low-porosity crypts in faster flow environments may therefore experience flow levels that are more similar to slowflow environments. Conversely, the occupants of high-porosity/fast-flow environments were subject to the full effects of the fast-flow conditions.

The overall greater biomass of certain taxa in the slow-flow environments could have been influenced by the higher coral cover in the benthic community of the slow-flow treatment site, as the percent of live coral cover there was $56 \%( \pm 16.5 \mathrm{SD})$ versus $38 \%$ $( \pm 21.4)$ at the fast-flow site. However, given that the presence/absence of living coral directly overlying the ARFs had no effect on the cryptic community below coupled with the high variability in this coral cover data, we hypothesize that the results are predominately due to the experimental treatments of porosity and flow.

Considering that 56 to $80 \%$ of coral mucus dissolves rapidly into surrounding seawater (Wild et al. 2004), it is not surprising that the overlying coral cover of the experimental treatments had no effect on the cryptofaunal communities occupying the underlying framework. In calm and oligotrophic conditions, the role of mucus may be significant; however, most coral reef environments are likely too turbulent for live coral cover to have direct impacts on the biomass of cryptofauna in the frameworks immediately surrounding them. Coral tissues and mucus are undoubtedly an important source of nutriment for many reef organisms. It is likely, however, that they must either be consumed directly from a colony's surface by micro- and macrobiota (McCloskey 1970, Enochs \& Hockensmith 2009), or from the water column and interstitial spaces by microorganisms (Wild et al. 2004). We hypothesize that the consumption of coral tissues or metabolic byproducts by cryptic metazoans is either extremely localized and limited to live colony surfaces (live coral associates) or, alternatively, that the nutritious impacts of corals are diffused across the reef in such a way that the majority of metazoans living in dead-frameworks adjacent to live corals are not conferred a trophic advantage over those in outlying areas. The results of our experiment therefore support the contention that, unlike live coral associates and symbionts (Caley et al. 2001, Coker et al. 2009), motile cryptofauna inhabiting dead reef frameworks are not strongly influenced by coral mortality or distributed according to live coral cover (Idjadi \& Edmunds 2006).

The structure of the ARF units allowed lateral colonization in addition to migration through the surfacefacing treatment substrate (live vs. dead coral), as is often possible on partially disturbed reef areas. The present study did not, therefore, directly assess the 
potential for live coral to inhibit the penetration of cryptofauna into underlying dead frameworks. In habitats with large expanses of uninterrupted live coral cover, however, colonization of cryptofauna to reef frameworks may be limited to the reef surface and therefore require that potential occupants pass through live coral tissues to enter coral crypts. In these areas, potentially deterrent or defensive qualities of the coral tissues may restrict colonization (Kirsteuer 1969, Hutchings 1985, Fonseca et al. 2006).

\section{Implications for ecosystem responses to habitat degradation}

The results of the present study provide important new insights into the spatial distribution of coral reef cryptofauna across environmental gradients and reef habitats, and also illustrate how cryptofaunal communities respond to ecosystem degradation. Motile coral reef cryptofauna were shown to be more abundant and have greater biomass in low-porosity, slow-flow environments, similar to those of sheltered back-reef rubble plains or deep fore-reef rubble margins. Small broken coral fragments may be of equal or greater importance in sheltering these organisms than open, intact frameworks. Therefore, given the great importance of cryptofauna in supporting complex coral reef food webs (Glynn \& Enochs 2011), conservation efforts and management strategies designed to preserve ecosystem function and trophic pathways need to consider classically 'less important' reef habitats, such as eroded areas, which may not have high live coral cover.

Similarly, bleaching and mass coral mortality may not have large immediate effects on frameworkdwelling cryptofaunal abundances, biomass, and biodiversity, though some taxa will certainly be affected. Overall cryptofaunal abundances may even increase during bioerosion of reef framework structures, suggesting that the important food webs these taxa support may be maintained through ecological disturbance (Moran \& Reaka 1988). Fish abundances have also been shown to increase initially after bleaching events, because of increased abundances of herbivorous taxa (Garpe et al. 2006). As with fishes (Garpe et al. 2006, Graham et al. 2007), habitat loss and extreme decreases in structural complexity over longer time periods will likely lead to the elimination of these cryptic communities and, by extension, other reef taxa that rely on them for food and for defense against predators.
Finally, these data suggest that reef structure, independent of live coral cover, is of paramount importance in supporting cryptofaunal communities. This conclusion has important implications for the efficacy of artificial reef habitats in maintaining reef ecosystem function in the absence of live coral. Artificial reefs have generally been shown to enhance the populations of commercially important fishes (Bohnsack \& Sutherland 1985, Claudet \& Pelletier 2004), but there has been some concern about the incomplete understanding of the biological functioning of artificial reefs (Bohnsack \& Sutherland 1985). Our results indicate that artificial reefs formed from materials similar to those in natural reef environments (e.g. rubble) are likely to support robust cryptofaunal communities provided that they are of sufficient structural complexity. These habitats may, in turn, contribute to enhanced fisheries production and provide a possible mechanism for the preservation of important reef biota in a time of pronounced coral reef degradation.

Acknowledgements. Support was provided by the LernerGray Fund and the American Museum of Natural History, National Science Foundation grant to Peter W. Glynn, No. OCE-0526361. A. Bakun, P. Glynn, C. Langdon, D. Lirman, and B. Riegl provided manuscript advice. A. Anker, A. Baeza, R. Brusca, Y. Camacho Garcia, G. Coan, J. Garcia-Gomez, G. Hendler, R. Lemaitre, H. Lessios, J. Llopiz, G. Paulay, L. Harris, A. Schulze, E. Schwabe, J. Thomas, and P. ValentichScott assisted in the identification of specimens. I. Chambers, A. Goodson, A. Gracie, D. Graham, A. Jung, J. Kelly, N. Kraft, L. O'Neill, A. Mallozzi, A. Pflaumer, and S. Thompson helped in the sorting and processing of specimens. We are very grateful for the advice of Peter W. Glynn, whose knowledge guided every stage of this research project.

\section{LITERATURE CITED}

Abele LG, Patton WK (1976) The size of coral heads and the community biology of associated decapod crustaceans. J Biogeogr 3:33-47

Airoldi L, Virgilio M (1998) Responses of turf-forming algae to spatial variations in the deposition of sediments. Mar Ecol Prog Ser 165:271-282

Anderson MJ (2001) A new method for non-parametric multivariate analysis of variance. Austral Ecol 26:32-46

Anderson MJ, Gorley RN, Clarke KR (2008) PERMANOVA + for PRIMER: guide to software and statistical methods. PRIMER-E, Plymouth

Bakus GJ (1966) Some relationships of fishes to benthic organisms on coral reefs. Nature 210:280-284

Bell JD, Galzin R (1984) Influence of live coral cover on coralreef fish communities. Mar Ecol Prog Ser 15:265-274

Bohnsack JA, Sutherland DL (1985) Artificial reef research: a review with recommendations for future priorities. Bull Mar Sci 37:11-39

> Buss LW, Jackson JBC (1981) Planktonic food availability 
and suspension-feeder abundance: evidence of in situ depletion. J Exp Mar Biol Ecol 49:151-161

> Caley MJ, Buckley KA, Jones GP (2001) Separating ecological effects of habitat fragmentation, degradation, and loss on coral commensals. Ecology 82:3435-3448

Cinelli F, Fresi E, Mazzella L, Pansini M, Pronzato R, Svoboda A (1977) Distribution of benthic phyto- and zoocoenoses along a light gradient in a superficial marine cave. In: Keegan BF, O'Ceidigh PO, Broaden PJS (eds) Biology of benthic organisms. Pergamon Press, Oxford, p 173-183

Claudet J, Pelletier D (2004) Marine protected areas and artificial reefs: a review of the interactions between management and scientific studies. Aquat Living Resour 17: $129-138$

Coen LD (1988) Herbivory by Caribbean majid crabs: feeding ecology and plant susceptibility. J Exp Mar Biol Ecol 122:257-276

Coker DJ, Pratchett MS, Munday PL (2009) Coral bleaching and habitat degradation increase susceptibility to predation for coral-dwelling fishes. Behav Ecol 20:1204-1210

Coles SL (1980) Species diversity of decapods associated with living and dead reef coral Pocillopora meandrina. Mar Ecol Prog Ser 2:281-291

de Goeij JM, van Duyl FC (2007) Coral cavities are sinks of dissolved organic carbon (DOC). Limnol Oceanogr 52: 2608-2617

Done TJ (1983) Coral zonation: its nature and significance. In: Barnes DJ (ed) Perspectives on coral reefs. Brian Clouston, Manuka, p 107-147

Edwards A, Emberton H (1980) Crustacea associated with the scleractinian coral, Stylophora pistillata (Esper), in the Sudanese Red Sea. J Exp Mar Biol Ecol 42: 225-240

Enochs IC, Hockensmith G (2009) Effects of coral mortality on the community composition of cryptic metazoans associated with Pocillopora damicornis. In: Proc 11th Coral Reef Symp, Ft. Lauderdale, FL, 2:1368-1372

Fonseca AC, Dean HC, Cortes J (2006) Non-colonial coral macro-borers as indicators of coral reef status in the South Pacific of Costa Rica. Rev Biol Trop 54:101-115

Garpe KC, Yahya SAS, Lindahl U, Öhman MC (2006) Longterm effects of the 1998 coral bleaching event on reef fish assemblages. Mar Ecol Prog Ser 315:237-247

Geister J (1977) The influence of wave exposure on the ecological zonation of Caribbean coral reefs. In: Proc 3rd Int Coral Reef Symp, Vol 1. University of Miami, Miami, FL, p 23-29

Ginsburg RN (1983) Geological and biological roles of cavities in coral reefs. In: Barnes D (ed) Perspectives on coral reefs. Australian Institute of Marine Science, Townsville, p 148-153

Gischler E, Ginsburg RN (1996) Cavity dwellers (coelobites) under coral rubble in southern Belize barrier and atoll reefs. Bull Mar Sci 58:570-589

> Glynn PW (1980) Defense by symbiotic Crustacea of host corals elicited by chemical cues from predator. Oecologia 47:287-290

Glynn PW (1983) Increased survivorship in corals harboring crustacean symbionts. Mar Biol Lett 4:105-111

Glynn PW (2006) Fish utilization of simulated coral reef frameworks versus eroded rubble substrates off Panama, eastern Pacific. In: Proc 10th Int Coral Reef Symp, Okinawa, 1:250-256

Glynn PW, Enochs IC (2011) Invertebrates and their roles in coral reef ecosystems. In: Dubinsky Z, Stambler N (eds) Coral reefs: an ecosystem in transition. Springer, New York, NY, p 273-325

Graham NAJ, Wilson SK, Jennings S, Polunin NVC, Robinson J, Bijoux JP, Daw TM (2007) Lag effects in the impacts of mass coral bleaching on coral reef fish, fisheries, and ecosystems. Conserv Biol 21:1291-1300

Holbrook SJ, Brooks AJ, Schmitt RJ (2002) Variation in structural attributes of patch-forming corals and in patterns of abundance of associated fishes. Mar Freshw Res 53:1045-1053

Hutchings PA (1985) Cryptofaunal communities of coral reefs. Acta Oceanol Sin 5:603-613

Hutchings PA, Weate PD (1977) Distribution and abundance of cryptofauna from Lizard Island, Great Barrier Reef. Mar Res Indones 17:99-112

> Hutchinson GE (1941) Ecological aspects of succession in natural populations. Am Nat 75:406-418

Hutchinson GE (1957) Concluding remarks. Cold Spring Harb Symp Quant Biol 22:415-427

Idjadi JA, Edmunds PJ (2006) Scleractinian corals as facilitators for other invertebrates on a Caribbean reef. Mar Ecol Prog Ser 319:117-127

Jones GP, McCormick MI, Srinivasan M, Eagle JV (2004) Coral decline threatens fish biodiversity in marine reserves. Proc Natl Acad Sci USA 101:8251-8253

Kirsteuer E (1972) Quantitative and qualitative aspects of the nemertean fauna in tropical coral reefs. In: Proc 1st Int Symp Corals and Coral Reefs, Mandapam Camp 1:363-371

Levin SA, Paine RT (1974) Disturbance, patch formation, and community structure. Proc Natl Acad Sci USA 71: 2744-2747

Leviten PJ, Kohn AJ (1980) Microhabitat resource use, activity patterns, and episodic catastrophe: Conus on tropical intertidal reef rock benches. Ecol Monogr 50:55-75

Martindale W (1992) Calcified epibionts as palaeoecological tools: examples from the Recent and Pleistocene reefs of Barbados. Coral Reefs 11:167-177

> McCloskey LR (1970) The dynamics of the community associated with a marine scleractinian coral. Int Rev Gesamten Hydrobiol Hydrograph 55:13-81

> Moran DP, Reaka ML (1988) Bioerosion and availability of shelter for benthic reef organisms. Mar Ecol Prog Ser 44: 249-263

Navas GR, Moreno-Forero SK, Solano OD, Díaz-Pulido G (1998) Ensamblajes arrecifales epilíticos del coral Acropora palmata muerto, Isla Grande, Islas del Rosario, Caribe Colombiano. Caribb J Sci 34:58-66

Nowell ARM, Jumars PA (1984) Flow environments of aquatic benthos. Annu Rev Ecol Syst 15:303-328

> Palardy JE, Witman JD (2011) Water flow drives biodiversity by mediating rarity in marine benthic communities. Ecol Lett 14:63-68

Peyrot-Clausade M (1977) Settlement of an artificial biota by coral reef cryptofauna. In: Proc 3rd Int Coral Reef Symp, Miami, FL 1:101-103

Peyrot-Clausade M (1989) Crab cryptofauna (Brachyura and Anomura) of Tikehau, Tuamotu Archipelago, French Polynesia. Coral Reefs 8:109-117

> Preston NP, Doherty PJ (1990) Cross-shelf patterns in the community structure of coral-dwelling Crustacea in the central region of the Great Barrier Reef. I. Agile shrimps. Mar Ecol Prog Ser 66:47-61

Preston NP, Doherty PJ (1994) Cross-shelf patterns in the 
community structure of coral-dwelling Crustacea in the central region of the Great Barrier Reef. II. Cryptofauna. Mar Ecol Prog Ser 104:27-38

Reaka ML (1987) Adult-juvenile interactions in benthic reef crustaceans. Bull Mar Sci 41:108-134

Reaka-Kudla ML (1997) The global biodiversity of coral reefs. In: Reaka-Kudla ML, Wilson DE, Wilson EO (eds) Biodiversity. II. Understanding and protecting our biological resources. Joseph Henry Press, Washington, DC, p 83-108

Rhoads DC, Young DK (1970) The influence of deposit feeding organisms on sediment stability and community structure. J Mar Res 28:150-178

Richter C, Wunsch M (1999) Cavity-dwelling suspension feeders in coral reefs - a new link in reef trophodynamics. Mar Ecol Prog Ser 188:105-116

Richter C, Wunsch M, Rasheed M, Kötter I, Badran MI (2001) Endoscopic exploration of Red Sea coral reefs reveals dense populations of cavity-dwelling sponges. Nature 413:726-730

Rothans TC, Miller AC (1991) A link between biologically imported particulate organic nutrients and the detritus food web in reef communities. Mar Biol 110:145-150

Scheffers SR, Van Soest RWM, Nieuwland G, Bak RPM (2010) Coral reef framework cavities: Is functional similarity reflected in composition of the cryptic macrofaunal community? Atoll Res Bull 583:1-24

Shirayama Y, Horikoshi M (1982) A new method of classifying the growth form of corals and its application to a field survey of coral-associated animals in Kabira Cove, Ishigaki Island. J Oceanogr Soc Jpn 38:193-207

Stimson J (1990) Stimulation of fat-body production in the polyps of the coral Pocillopora damicornis by the presence of mutualistic crabs of the genus Trapezia. Mar Biol

Editorial responsibility: Tim McClanahan,

Mombasa, Kenya
106:211-218

Takada Y, Abe O, Shibuno T (2007) Colonization patterns of mobile cryptic animals into interstices of coral rubble. Mar Ecol Prog Ser 343:35-44

$>$ Takada Y, Abe O, Shibuno T (2008) Cryptic assemblages in coral-rubble interstices along a terrestrial-sediment gradient. Coral Reefs 27:665-675

Valles H, Kramer DL, Hunte W (2006) A standard unit for monitoring recruitment of fishes to coral reef rubble. J Exp Mar Biol Ecol 336:171-183

van Duyl FC, Scheffers SR, Thomas FIM, Driscoll M (2005) The effect of water exchange on bacterioplankton depletion and inorganic nutrient dynamics in coral reef cavities. Coral Reefs 25:23-36

Vivien ML, Peyrot-Clausade M (1974) A comparative study of the feeding behaviour of three coral reef fishes (Holocentridae), with special reference to the polychaetes of the reef cryptofauna as prey. In: Proc 2 nd Int Coral Reef Symp 1:179-192

> Vytopil E, Willis BL (2001) Epifaunal community structure in Acropora spp. (Scleractinia) on the Great Barrier Reef: implications of coral morphology and habitat complexity. Coral Reefs 20:281-288

Wild C, Huettel M, Klueter A, Kremb SG, Rasheed MYM, Jørgensen BB (2004) Coral mucus functions as an energy carrier and particle trap in the reef ecosystem. Nature 428:66-70

Wunsch M, Al-Moghrabi SM, Kötter (2000) Communities of coral reef cavities in Jordan, Gulf of Aqaba (Red Sea). In: Proc 9th Int Coral Reef Symp, Bali 1:595-600

Zimmerman TL, Martin JW (2004) Artificial reef matrix structures (ARMS): an inexpensive and effective method for collecting coral reef-associated invertebrates. Gulf Caribb Res 16:59-64

Submitted: February 14, 2011; Accepted: June 10, 2011 Proofs received from author(s): September 16, 2011 